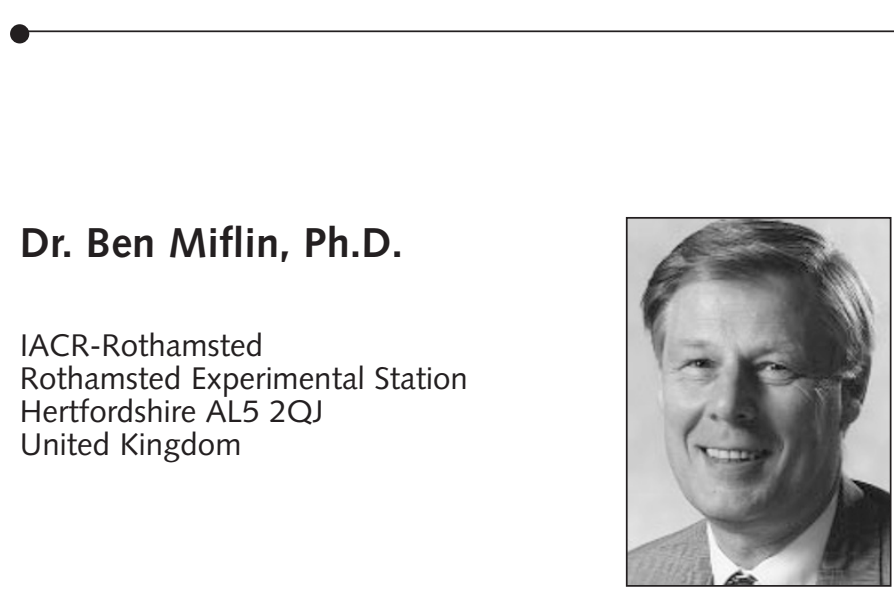

Ben Miflin is a Special Professor at the University of Nottingham and Lawes Trust Senior Fellow at IACRRothamsted. He has previously been Director of IACR and IACR Rothamsted, Head of Ciba Seeds International R\&D, Head of the Biochemistry Department at Rothamsted, and Lecturer at the University of Newcastle upon Tyne. He is a former member of the Advisory Committee on Novel Foods and Processes and former director of the International Society for Plant Molecular Biology.

\section{Consumer Benefits: Is the Public Being Sold Short by the NGOs?}

As a consumer I want the following from crop agriculture: sufficient food, fairly priced, healthy, and low risk. What's more, I want it produced in a way that has as little unnecessary impact on the ecosystem outside of agriculture as possible. Moreover, I want my children and grandchildren to have the same possibility in the future. I also consider it a responsibility of the Western world, where we can, to help those in the developing world to achieve their objectives in terms of food supply in the future. This means that we will need to produce $40 \%$ more crops for the expected 8 billion people by the year 2020-without increasing the amount of land and with a more efficient use of water. In this talk, I want to consider how far agbiotech has already moved to meet these needs and whether the activities of the NGOs who claim to be representing me and other consumers are actually meeting my objectives.

In this regard, there are several facts that should be considered. For example, a central issue with the food derived from any method of agriculture is the presence of antinutritional or toxic resides such as mycotoxins or pesticides. Analysis of genetically modified (GM) crops in commercial production since 1996 shows that their use has decreased the use of pesticides. Bt-cotton growers use half the insecticides of non-GM growers, $B t$ maize has produced up to $15 \%$ more grain with a lower likelihood of mycotoxin contamination. 1,2 Moreover, these results are already having an impact on developing nations: The first "commercial" transgenic crops were grown in China and many examples of technology transfer to developing countries have been documented. ${ }^{3}$

What has been the response of the NGOs to these results? It has been to whip up hysteria about food safety and the dangers to the environment. So far, there have been no adverse effects of any GM crop identified. The inconsistency between the facts relating to commercial GM crops and the stated aims of many NGOs and their actions suggest their motives may be contrary to stated intentions.

1. Gianessi, LP \& Carpenter, JE. Agricultural Biotechnology: Insect Control Benefits Report of National Center for Food and Agricultural Policy (July 1999).

2. Munkvold, GP et al. Plant Dis. 83: 130-138 (1999).

3. Salamini, F. Nature Biotechnology 17 (Suppl) BV 11 (1999). 